\title{
Anti-proliferative but not anti-angiogenic tyrosine kinase inhibitors enrich for cancer stem cells in soft tissue sarcoma
}

\author{
Robert J Canter ${ }^{1 *}$, Erik Ames², Stephanie Mac², Steven K Grossenbacher ${ }^{2}$, Mingyi Chen ${ }^{3}$, Chin-Shang Li,
} Dariusz Borys ${ }^{3}$, Rachel C Smith², Joe Tellez ${ }^{2}$, Thomas J Sayers ${ }^{5}$, Arta M Monjazeb ${ }^{6}$ and William J Murphy ${ }^{7}$

\begin{abstract}
Background: Increasing studies implicate cancer stem cells (CSCS) as the source of resistance and relapse following conventional cytotoxic therapies. Few studies have examined the response of CSCs to targeted therapies, such as tyrosine kinase inhibitors (TKIs). We hypothesized that TKIs would have differential effects on CSC populations depending on their mechanism of action (anti-proliferative vs. anti-angiogenic).

Methods: We exposed human sarcoma cell lines to sorafenib, regorafenib, and pazopanib and assessed cell viability and expression of CSC markers (ALDH, CD24, CD44, and CD133). We evaluated survival and CSC phenotype in mice harboring sarcoma metastases after TKI therapy. We exposed dissociated primary sarcoma tumors to sorafenib, regorafenib, and pazopanib, and we used tissue microarray (TMA) and primary sarcoma samples to evaluate the frequency and intensity of CSC markers after neoadjuvant therapy with sorafenib and pazopanib. Parametric and non-parametric statistical analyses were performed as appropriate.

Results: After functionally validating the CSC phenotype of ALDH ${ }^{\text {bright }}$ sarcoma cells, we observed that sorafenib and regorafenib were cytotoxic to sarcoma cell lines $(P<0.05)$, with a corresponding $1.4-2.8$ fold increase in $A L D H^{\text {bright }}$ cells from baseline $(P<0.05)$. In contrast, we observed negligible effects on viability and CSC sub-populations with pazopanib. At low doses, there was progressive CSC enrichment in vitro after longer term exposure to sorafenib although the anti-proliferative effects were attenuated. In vivo, sorafenib improved median survival by 11 days $(P<0.05)$, but enriched ALDH $H^{\text {bright }}$ cells 2.5 - 2.8 fold $(P<0.05)$. Analysis of primary human sarcoma samples revealed direct cytotoxicity following exposure to sorafenib and regorafenib with a corresponding increase in ALDH ${ }^{\text {bright }}$ cells $(P<0.05)$. Again, negligible effects from pazopanib were observed. TMA analysis of archived specimens from sarcoma patients treated with sorafenib demonstrated significant enrichment for $\mathrm{ALDH}^{\text {bright }}$ cells in the post-treatment resection specimen $(P<0.05)$, whereas clinical specimens obtained longitudinally from a patient treated with pazopanib showed no enrichment for ALDH bright cells $(P>0.05)$.
\end{abstract}

Conclusions: Anti-proliferative TKIs appear to enrich for sarcoma CSCs while anti-angiogenic TKIs do not. The rational selection of targeted therapies for sarcoma patients may benefit from an awareness of the differential impact of TKls on CSC populations.

Keywords: Soft tissue sarcoma, Cancer stem cells, Tyrosine kinase inhibitors, Sorafenib, Pazopanib, Regorafenib, ALDH

\footnotetext{
* Correspondence: Robert.canter@ucdmc.ucdavis.edu

${ }^{1}$ Department of Surgery, Division of Surgical Oncology, University of

California Davis Medical Center, 4501 X Street, Sacramento, CA 95817, USA

Full list of author information is available at the end of the article
} 


\section{Background}

The cancer stem cell (CSC) hypothesis postulates that CSCs, also referred to as tumor-initiating cells, represent a small proportion of malignant cells in the overall tumor bulk $[1,2]$. It is these typically quiescent cells which are resistant to conventional cytotoxic cancer therapies and which are able to repopulate tumors even after apparent complete response to chemotherapy and/or radiotherapy (RT) [3-5]. The presence of CSC subpopulations has been identified in nearly all human malignancies, and mounting studies of CSC engraftment in long term culture and immune-compromised mice have validated the CSC phenotype [6-8]. Moreover, genetic lineage tracing studies have provided provocative evidence for the existence of CSCs in a hierarchy of asymmetric cell division and tumor repopulation in models of squamous cell carcinoma, intestinal adenomas, and GBM. These studies provide the highest level evidence to date that CSCs are clinically and biologically significant $[3,9,10]$.

Numerous CSC markers have been identified and characterized, including cell surface markers such as CD24, CD44, and CD133, and the intracellular enzyme aldehyde dehydrogenase (ALDH), among others $[1,8,11,12]$. Although investigators have observed the expression of CSC markers to vary depending on experimental conditions and tumor type, ALDH has been consistently identified as a CSC marker in breast cancer and prostate cancer, and levels of ALDH ${ }^{\text {bright }}$ cells have been observed to predict worse oncologic outcome in numerous human cancers, including soft tissue sarcoma (STS) [7,13-18]. Awad et al., for example, identified an ALDH ${ }^{\text {bright }}$ subpopulation of Ewing's sarcoma cells which was able to stimulate long term colony outgrowth, form tumor xenografts in immunodeficient mice, and resist chemotherapy treatment [19].

Although CSCs are considered resistant to standard anti-cancer therapies such as chemotherapy and RT, few studies have examined the effects of tyrosine kinase inhibitors (TKIs) on CSCs, particularly the differential effects of TKIs depending on their mechanism of action. Sorafenib is a pleotropic TKI which exerts its activity primarily by direct effects on cell proliferation via inhibition of C-Raf and B-Raf [20]. Sorafenib is FDA-approved for the treatment of advanced renal, liver, and thyroid cancer [21], and Phase II studies of sorafenib have demonstrated activity and clinical benefit for patients with metastatic STS $[22,23]$. A recently completed Phase I trial demonstrated safety and preliminary data for activity in locally advanced extremity STS [24]. Regorafenib is a second generation multi-kinase inhibitor with activity and mechanism of action similar to sorafenib [25]. Regorafenib is approved for the treatment of metastatic colon cancer and advanced gastrointestinal stromal tumors [26]. In contrast, pazopanib is a potent inhibitor of angiogenesis [27]. In a recently completed international phase III trial for patients with metastatic STS, pazopanib reduced the risk of tumor progression or death approximately $70 \%$, leading to its approval for STS by the FDA in 2013 [28]. Pazopanib is also approved for the treatment of patients with advanced renal cell carcinoma [29].

Given the increasing clinical use of targeted therapies such as TKIs in clinical oncology including STS as well as the evidence suggesting that specific tyrosine kinases may promote the CSC phenotype [30], we sought to determine the effects of TKIs on whole tumor bulk and CSC populations in diverse models of STS. We hypothesized that there would be differential effects of TKIs on CSC populations depending on their mechanism of action and that enrichment for sarcoma CSCs would be more prevalent with anti-proliferative TKIs rather than anti-angiogenic TKIs.

\section{Methods}

\section{Tumor cell lines}

Human sarcoma cell lines (A673 Ewing's sarcoma, SW-982 synovial sarcoma, and SK-LMS leiomyosarcoma) were obtained from the American Type Culture Collection (Manassas, VA) and maintained in the recommended tissue culture medium supplemented with $10 \%$ heat-inactivated fetal calf serum, L-glutamine, penicillin G, streptomycin, amphotericin, and gentamycin.

\section{Materials}

Sorafenib p-Tosylate salt, regorafenib, and pazopanib free base were obtained from LC Laboratories (Woburn, MA). For in vitro experiments, compounds were dissolved in a stock solution of $100 \%$ DMSO and then diluted to final concentration of $0.2 \%$ DMSO. Stock solutions were replenished every 4-6 weeks per manufacturer's recommendations. For in vivo experiments, sorafenib was protected from light, dissolved in 10\% DMSO, 10\% cremaphor, and $80 \%$ sterile PBS, and sterile-filtered through $0.2 \mu \mathrm{M}$ pores (Cole-Parmer, Chicago, IL). Daily intraperitoneal (i.p.) injections were administered using fresh sorafenib. Placebo animals received i.p. injections containing 10\% DMSO, $10 \%$ cremaphor, and $80 \%$ sterile PBS.

\section{ALDEFLUOR $^{\text {TM }}$ assay and flow cytometry}

ALDEFLUOR $^{\text {Th }}$ expression (STEMCELL Technologies, Vancouver, BC, Canada) was determined according to the manufacturers' instructions using diethylaminobenzaldehyde (DEAB) to inhibit ALDH activity and to control for background fluorescence (Additional file 1: Figure S1). Pacific Blue anti-human CD45 (HI30) and 7-AAD were purchased from BD Biosciences (San Jose, CA). PE-Cy7 anti-human CD24 and Pacific Blue antihuman CD44 were purchased from BioLegend (San 
Diego, CA). PE anti-human CD133 was purchased from Miltenyi Biotec (Auburn, CA). All samples were acquired on an LSR Fortessa with HTS (BD Biosciences, San Jose, $\mathrm{CA}$ ) and analyzed with FlowJo software (TreeStar, Ashland, OR).

\section{Animals and tumor cell implantation}

Female NOD.Cg-Prkdc $c^{\text {scid }} I l 2 r g^{t m 1 W j l} / \mathrm{SzJ}$ (NSG) mice, aged 7 - 8 weeks, were obtained from The Jackson Laboratory (Bar Harbor, ME) and housed under specific pathogen-free conditions. For subcutaneous/flank tumor inoculation, cells were harvested from $80 \%$ confluent cell culture conditions, counted, and resuspended in sterile PBS at a concentration of $25 \times 10^{6} / \mathrm{mL}$. A total of $5 \times 10^{6}$ cells in $200-\mu \mathrm{L}$ aliquots were then injected subcutaneously into the dorsal-lateral aspect of the flank. Tumors were allowed to grow to $3-5 \mathrm{~mm}$ in maximal dimension prior to initiating treatment. For intravenous tumor inoculation, cells were resuspended in sterile PBS at a concentration of $2 \times 10^{6} / \mathrm{mL}$, and a total of $2 \times 10^{6}$ cells in $1-\mathrm{mL}$ aliquots were then injected by tail vein. Tumors were allowed to grow for approximately 3 weeks by which time multiple lung and liver metastases were reproducibly visible on necropsy studies prior to initiating treatment. All experimental protocols were approved by the UC Davis Institutional Animal Care and Use Committee.

\section{Xenograft tumor evaluation}

Mice were euthanized at indicated time points. Lung and liver metastases were excised and manually dissociated in PBS to create an homogenous slurry. Collagenase I $(1 \mathrm{mg} / \mathrm{mL})$ and DNAase $(0.1 \mathrm{mg} / \mathrm{mL})$ were dissolved in $2 \%$ BSA (weight/volume), filtered using a $0.22 \mu \mathrm{M}$ sterile filter (Pall Life Sciences), and mixed with tumor slurry. Samples were incubated at $37^{\circ} \mathrm{C}$ for one hour, filtered sequentially using $100 \mu \mathrm{M}, 70 \mu \mathrm{M}$, and $40 \mu \mathrm{M}$ filters (BD Biosciences, ), centrifuged at $1200 \mathrm{rpm}$ for 5 minutes, resuspended in PBS, and counted using a Coulter Counter. Repeat centrifugation was performed, and tumor cells were resuspended at PBS at $1-2 \times 10^{6}$ cells per $\mathrm{mL}$ for flow cytometry.

\section{Histology and immunohistochemistry}

Xenograft tumor samples were fixed for $24-48$ hours in $10 \%$ formalin and then transferred to $90 \%$ ethanol. Hematoxylin and eosin (H\&E) slides were reviewed in a blinded fashion by a pathologist (M.C./D.B.). Percent histologically intact tumor and percent necrotic tumor were scored per slide, and mean percent tumor necrosis was calculated for the entire specimen, excluding nonneoplastic tissue. Approximately $5-10 \mathrm{H}$ \& E slides were examined per animal.

\section{Evaluation of primary sarcoma samples}

Primary STS and benign tumor resections (SA-0689, CCS0015-012, CCS0015-010, SA-0624, and SA-0751) were obtained immediately after surgical excision through the UC Davis Comprehensive Cancer Center Biorepository. Informed consent was obtained from all patients before tissue procurement under the auspices of the Institutional Review Board of UC Davis. Primary STS tumor samples were processed into single cell suspensions for CSC phenotyping and ex vivo exposure to TKIs as described above. CD45 negative selection was used to exclude nonneoplastic myeloid and lymphoid cells from analysis, and 7AAD viability dye was used to exclude dead cells.

\section{Evaluation of archived clinical sarcoma samples}

Tissue microarrays (TMA) were constructed using formalin-fixed, paraffin-embedded clinical sarcoma specimens obtained by the UC Davis Cancer Center Biorepository (CCBR) Core Facility. Eight patients were previously treated on a phase I clinical trial protocol (UCDCC\#216, NCT) using neoadjuvant sorafenib and RT for locally advanced extremity STS prior to resection with curative intent [24]. Eight STS patients who were treated with primary surgical resection (without neoadjuvant sorafenib and RT) were used as controls. IRB approval for this retrospective analysis of prospectively collected STS tumor tissue was obtained from the Institutional Review Board of UC Davis.

Following antigen retrieval and blocking, TMA sections $(4 \mu \mathrm{m})$ were immunostained using a commerciallyavailable purified mouse anti-human ALDH1 antibody (BD Transduction Laboratories, San Jose, CA) with appropriate positive and negative controls. We used the avidin-biotin complex method (DAKO) with 3,3'-diaminobenzidine $(\mathrm{DAB})$ for visualization. Stained slides were reviewed by a pathologist (M.C.) who was blinded to the clinical outcome and scored for percentage and intensity of ALDH1-positive cells. The product of the percentage of cells staining positive and the staining intensity was then calculated as described previously.

\section{Statistical considerations}

Summary statistics were reported as mean \pm standard error with median (range) where appropriate. Categorical variables were compared using a chi-squared test. Parametric continuous variables were compared using an independent samples t-test. Non-parametric continuous variables were compared using the MannWhitney U test. For comparison of more than 2 groups, statistical significance was determined using a one-way ANOVA followed by a Bonferroni multiple-group comparison test. Survival curves were evaluated using the Kaplan-Meier method. ALDH scores before and after 
treatment were analyzed using the two-sided paired t-test. Statistical analyses were performed using SAS version 9.2 (SAS Institute Inc., Cary, NC) and Graph-Pad Prism 5. Significance was set at $\mathrm{P}<0.05$.

\section{Results}

$\mathrm{ALDH}^{\text {bright }}$ sarcoma cells display CSC properties

We first validated the CSC phenotype of ALDH ${ }^{\text {bright }}$ A673 Ewing's sarcoma cells. After sorting cells by FACS into $\mathrm{ALDH}^{\text {bright }}$ and $\mathrm{ALDH}^{\mathrm{dim}}$ sub-populations, we observed ALDH ${ }^{\text {bright }}$ cells were able to sustain long term survival in vitro (data not shown) and to form tumor xenografts in NSG mice (Additional file 2: Figure S2). ALDH ${ }^{\text {bright }}$ cells established tumors faster and were more rapidly fatal than $\mathrm{ALDH}^{\mathrm{dim}}$ cells $(\mathrm{P}<0.05)$. We also observed marked differences in tumor growth and volume between ALDH ${ }^{\text {bright }}$ and $\mathrm{ALDH}^{\mathrm{dim}}$ populations on visual inspection at necropsy (Additional file 1: Figure S1B) and using T1- and T2-weighted MRI (Additional file 1: Figure S1C). In contrast, we observed CD24, CD44, and CD133 to be variably expressed in our sarcoma cell lines, and we found that these markers did not reliably correlate with the CSC phenotype (Additional file 1: Figure S1D).

\section{Dose dependent TKI effects in vitro}

As depicted in Figure 1, we tested the dose-dependent effects of overnight exposure to sorafenib, pazopanib, and regorafenib on three human sarcoma cell lines. All three cell lines (Figure $1 \mathrm{~A}-\mathrm{C}$ ) were sensitive to the cell killing effects of sorafenib at doses ranging from 8-64 $\mu \mathrm{M}$, while pazopanib had no effect on cell viability and regorafenib demonstrated cell killing comparable to sorafenib (Figure 1G).

Concomitant with its anti-proliferative effects, sorafenib also enriched for ALDH ${ }^{\text {bright }}$ sarcoma CSCs in all three cell lines (Figure 1D-F). Interestingly, we observed the greatest CSC enrichment at lower doses of sorafenib than those which caused the greatest antiviability effects. In A673 cells, for example, the ALDH ${ }^{\mathrm{b}-}$ right population increased from $9.5 \pm 0.7 \%$ at baseline to $13.3 \pm 1.3 \%$ at $4 \mu \mathrm{M}(1.4 \mathrm{X}$ increase, $\mathrm{P}<0.001)$ before dropping to $1.1 \pm 1.1 \%$ at $32 \mu \mathrm{M}$, likely representing induction of cell death for both CSC and non-CSC population at higher doses. Similarly, sorafenib exposure enriched the ALDH ${ }^{\text {bright }}$ population in SK-LMS cells (Figure 1E) from $6.8 \pm 2.4 \%$ at baseline to a peak of $19.3 \pm 1.5 \%$ at $4 \mu \mathrm{M}$ sorafenib $(2.8 \mathrm{X}$ increase, $\mathrm{P}<0.001)$. We also observed sorafenib enrichment for the ALDH ${ }^{\text {bright }}$ sub-population in SW982 cells (Figure 1F) with the proportion rising from $48.1 \pm 6.3 \%$ at $0 \mu \mathrm{M}$ sorafenib to a peak of $76.7 \pm 4.2 \%$ at $16 \mu \mathrm{M}$ sorafenib (1.6X increase, $\mathrm{P}<0.001)$. Compared to sorafenib, we did not observe any significant changes in the ALDH ${ }^{\text {bright }}$ populations of these cell lines following exposure to pazopanib, while regorafenib demonstrated similar CSC enrichment to sorafenib in SW982 cells (Figure 1H).

\section{Time dependent effects in vitro}

We then wanted to determine if longer exposure to these TKIs increased the sensitivity of these cell lines to cell killing or CSC enrichment. At $4 \mu \mathrm{M}$ sorafenib (Figure 2A), A673 cells remained insensitive to sorafenib, even with 3 day exposure to the drug. In contrast, culture at $32 \mu \mathrm{M}$ sorafenib led to a cumulative loss of $87.6 \pm 1.8 \%$ viable cells on day $2(\mathrm{P}<0.001)$ and $95.5 \pm 1.4 \%$ on day $3(\mathrm{P}<$ 0.001). With SK-LMS cells (Figure $2 \mathrm{~B}$ ), we also observed relatively negligible changes in viability following 3-day exposure to $4 \mu \mathrm{M}$ sorafenib, aside from a transient decrease in viability compared to controls on day 2 . Similar to A673 cells, at high dose sorafenib $(32 \mu \mathrm{M})$, we observed progressive decreases in SK-LMS cell viability over time, decreasing to $73.7 \pm 4.9 \%$ on day $1,47.1 \pm 6.5 \%$ on day 2 , and $34.4 \pm 6.7 \%$ on day 3 , respectively $(\mathrm{P}<0.001)$. The results of 3-day culture with pazopanib and regorafenib (Figure 2E) paralleled those we observed with overnight culture. There was no effect of $4 \mu \mathrm{M}$ pazopanib on SKLMS viability after 3 days, while $32 \mu \mathrm{M}$ regorafenib was comparable to sorafenib with a cumulative drop in viability to $52.1 \pm 3.5 \%(\mathrm{P}<0.001)$.

We also observed differences in the time-dependent effects of sorafenib on CSC enrichment in vitro. In A673 cells (Figure $2 \mathrm{C}$ ), we observed a progressive enrichment in $\mathrm{ALDH}^{\text {bright }}$ cells with long term exposure to $4 \mu \mathrm{M}$ sorafenib, reaching $39.4 \pm 2.8 \%$ on day $3(\mathrm{P}<0.001)$. Conversely, at $32 \mu \mathrm{M}$ sorafenib, the percentage of ALDH ${ }^{\text {bright }}$ cells declined to $0.5 \pm 0.9 \%$ and $0 \pm 0 \%$ after 2 and 3 days of sorafenib exposure, respectively $(\mathrm{P}<0.001)$. In SK-LMS cells (Figure 2D), there was a cumulative enrichment in $\mathrm{ALDH}^{\text {bright }}$ cells at day 2 and day 3 of exposure to 4 and $32 \mu \mathrm{M}$ sorafenib, respectively, whereas there was no significant change in the percentage of ALDH ${ }^{\text {bright }}$ cells over 3 days among the vehicle-treated controls.

From these data, we concluded that longer exposure to low dose sorafenib led to persistent CSC enrichment without any increase in anti-proliferative effects, suggesting a possible mechanism of resistance to the drug at lower doses. High dose sorafenib was effective at inducing cell death in both CSC and non-CSC populations in A673 cells, but in SK-LMS cells there was less sensitivity to the drug and a corresponding progressive enrichment in $\mathrm{ALDH}^{\text {bright }}$ cells, also suggesting that enrichment in CSC populations may correlate with drug resistance.

\section{Sorafenib exerts anti-proliferative effects in vivo while enriching for sarcoma CSCs}

We then tested the effects of sorafenib in an in vivo model. Injection of A673 cells into NSG mice by tail vein reproducibly produced lung and liver metastases after 21 days. We 


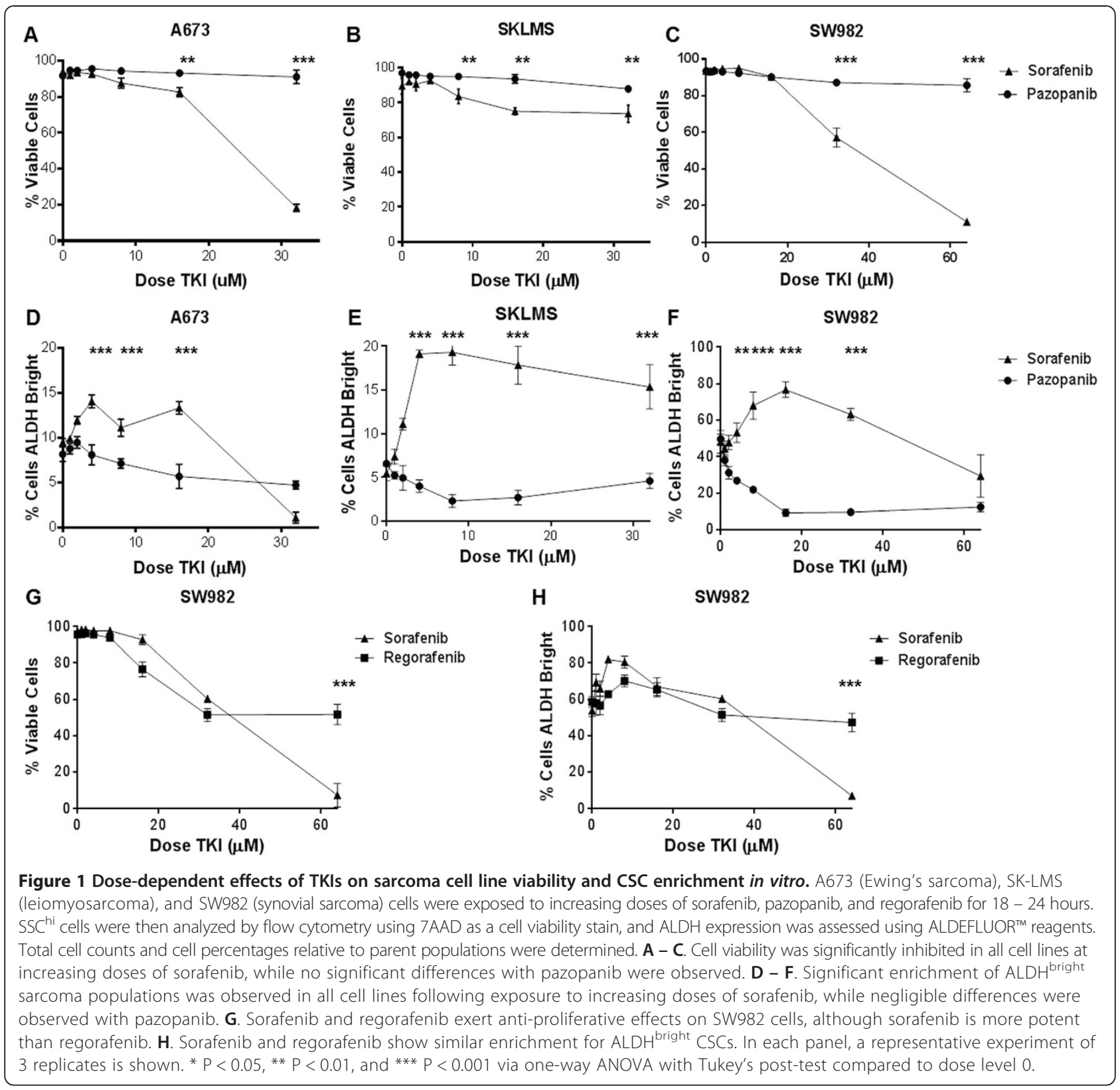

then treated mice in groups of 4-5 with daily injections of i.p. sorafenib or vehicle until tissues were harvested or survival studies were completed (Figure 3A). Previous studies have observed in vivo effects of sorafenib at doses ranging from $30-100 \mathrm{mg} / \mathrm{kg}[20,31]$. Although we observed a linear relationship between sorafenib dose in vivo and tumor growth delay, $100 \mathrm{mg} / \mathrm{kg}$ was toxic to approximately $10 \%$ of animals. Therefore, we opted to use $75 \mathrm{mg} / \mathrm{kg}$ as the in vivo dose of sorafenib.

As shown in Figure 3B, we observed that sorafenib prolonged survival in vivo by a median of 11 days from 18 days post-initiation of treatment to 29 days $(\mathrm{P}=0.03)$. Histological evaluation of tumors after sorafenib treatment revealed a statistically significant increase in tumor necrosis (Figure 3C). On day 7 post-treatment, percent tumor necrosis was $6.0 \pm 2.2 \%$ in placebo-treated animals vs. $32.0 \pm 2.7 \%$ in sorafenib-treated animals $(\mathrm{P}<0.001)$. There was also a significant increase in percent tumor necrosis in sorafenib-treated animals on day 12 posttreatment $(\mathrm{P}<0.001)$. Figure3D shows representative micrographs of tumor histology from placebo-treated and sorafenib-treated animals, respectively.

As shown in Figure 3E, tumor cell proliferation as measured by Ki-67 staining was significantly higher in placebo-treated than sorafenib-treated animals. In placebotreated animals, the percentage of Ki-67 positive cells was 


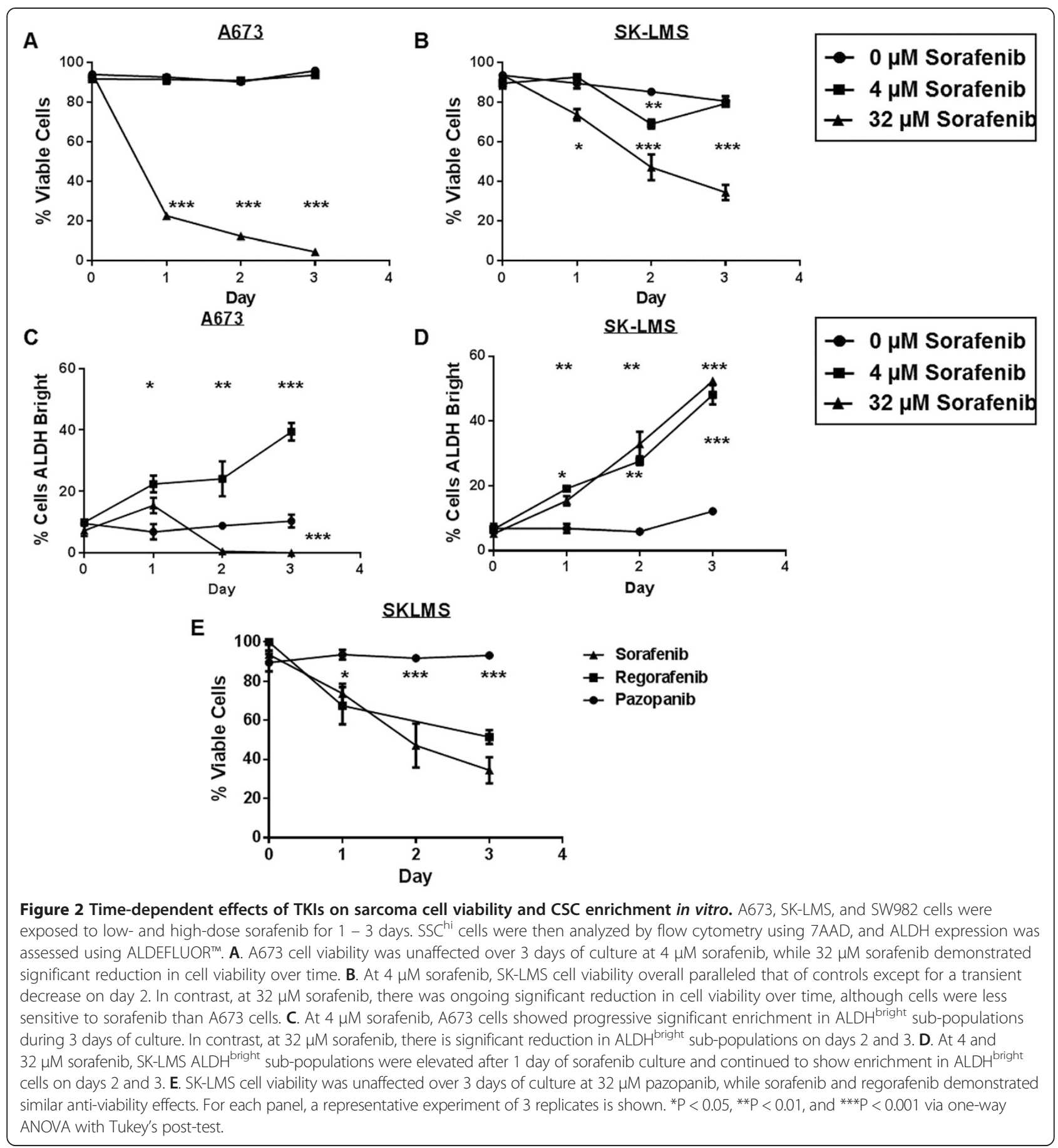

$82 \pm 6 \%$ and $81 \pm 4 \%$ on days 7 and 12 post-treatment, respectively. In contrast, in sorafenib-treated animals, the percentage of $\mathrm{Ki}-67$ positive cells was $51 \pm 4 \%$ and $53 \pm 10 \%$ on days 7 and 12 post-treatment, respectively $(\mathrm{P}<0.001)$. Non-viable, necrotic areas were excluded from the calculation of Ki-67 staining.

We then evaluated A673 xenografts for changes in ALDH ${ }^{\text {bright }}$ populations after sorafenib and placebo treatment. On day 7 post-treatment (Figure 3G), we observed the ALDH ${ }^{\text {bright }}$ sub-population to be significantly higher in sorafenib-treated tumors than placebo-treated tumors $(\mathrm{P}<0.001)$. Similarly, on day 12 post-treatment (Figure $3 \mathrm{H}$ ), we observed the ALDH ${ }^{\text {bright }}$ sub-population to be higher in the sorafenib-treated animals than placebo-treated ones, $0.72 \pm 0.08 \%$ vs. $0.25 \pm 0.09 \%$, respectively $(\mathrm{P}<0.001)$. Although the absolute differences in 


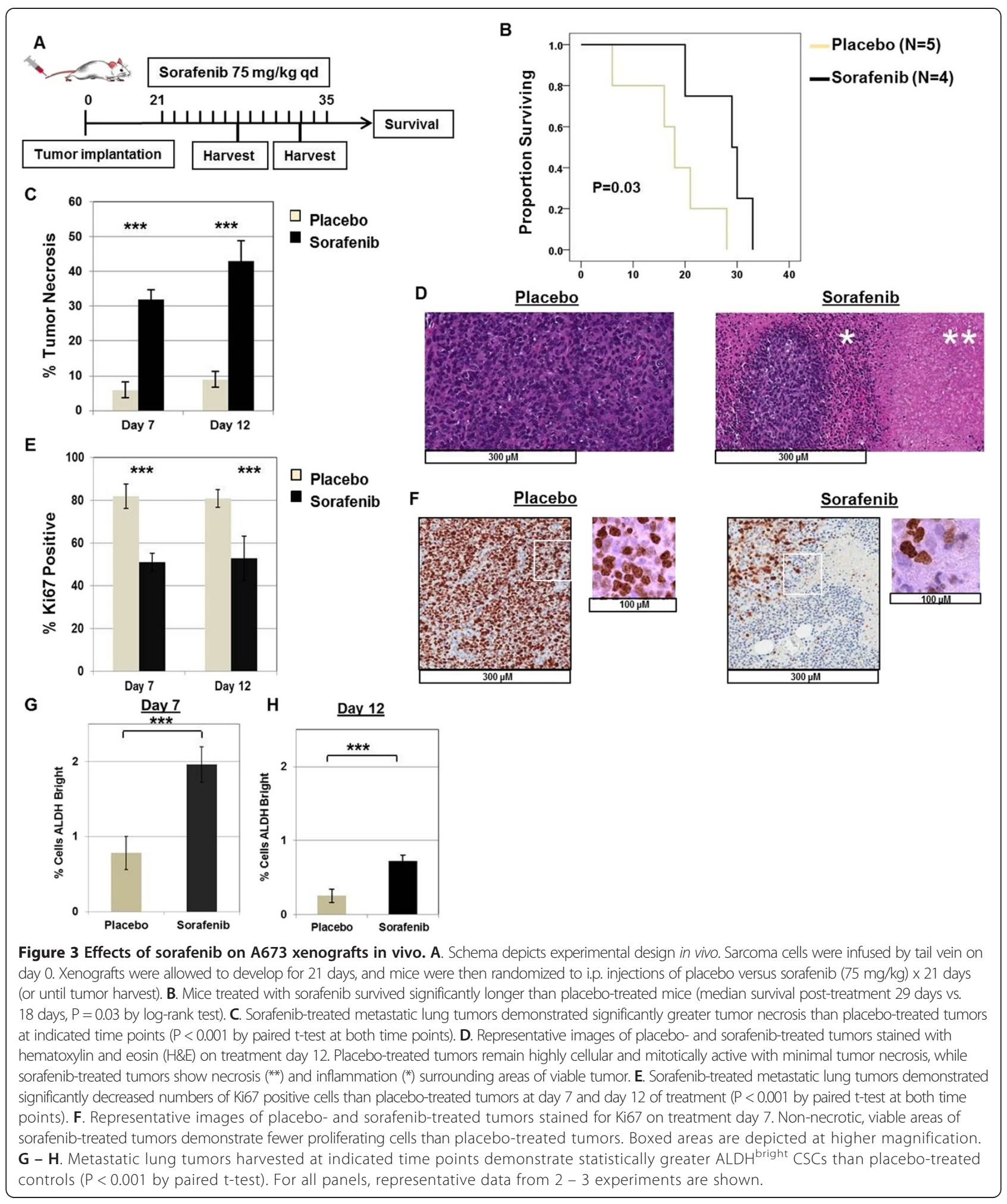

$\mathrm{ALDH}^{\text {bright }}$ sub-populations between placebo and sorafenibtreated animals were relatively modest, these differences nevertheless represented 2.5-2.9 fold enrichment in the CSC population at both time points.
Based on these data, we concluded that sorafenib exerts anti-proliferative effects in vivo while simultaneously enriching for CSCs, suggesting a preferential antiproliferative effect on the non-CSCs. 


\section{Sorafenib is cytotoxic to human primary sarcomas ex vivo but enriches for sarcoma CSCs}

We then analyzed the effects of TKIs on tumor cells freshly isolated from STS specimens (and benign soft tissue tumors) obtained at the time of surgical resection. There was marked patient to patient heterogeneity of tumor cells and the percentage of ALDH ${ }^{\text {bright }}$ cells detected at baseline (Figure 4A-D). Leiomyosarcoma cells from patient SA-0689 (Figure 4A) decreased in viability from $61.3 \pm 2.6 \%$ at baseline to $44.3 \pm 0.2 \%$ and $39.7 \pm 0.4 \%$ at $32 \mu \mathrm{M}$ and $64 \mu \mathrm{M}$ sorafenib, respectively $(\mathrm{P}<0.001)$ with a corresponding enrichment in ALDH ${ }^{\text {bright }}$ cells from $10.4 \pm 0.5 \%$ at baseline to a peak of $15.0 \pm 0.7 \%$ at $8 \mu \mathrm{M}$ sorafenib $(\mathrm{P}<0.001)$. For patient CCS0015-010 (Figure 4B), sorafenib decreased the viability of dedifferentiated liposarcoma cells from $26.9 \pm 0.5 \%$ at baseline to $11.2 \pm 0.6 \%$ at $32 \mu \mathrm{M}$ sorafenib $(\mathrm{P}<0.01)$ and $6.6 \pm 0.3 \%$ at $64 \mu \mathrm{M}$ sorafenib $(\mathrm{P}<0.001)$, respectively. There was simultaneous enrichment for the ALDH ${ }^{\text {bright }}$ sub-population which increased from $24.9 \pm 0.8 \%$ at baseline to $42.4 \pm 1.6 \%$ at $64 \mu \mathrm{M}$ sorafenib $(\mathrm{P}<0.001)$.

Leiomyosarcoma cells from patient CCS0015-012 (Figure 4B) were highly sensitive to sorafenib ex vivo with a dose-dependent decrease in viability from $90.5 \pm$ $0.3 \%$ at baseline to $18.2 \pm 1.3 \%$ at $64 \mu \mathrm{M}$ sorafenib $(\mathrm{P}<0.001)$. These tumor cells demonstrated intermediate sensitivity to regorafenib, while there was no significant change in viability following pazopanib exposure. Simultaneously, there was a corresponding enrichment in CCS0015-012 ALDH ${ }^{\text {bright }}$ cells following exposure to both sorafenib and regorafenib. Interestingly, similar to our in vitro experiments, CSC enrichment following sorafenib peaked at lower doses of sorafenib $(16 \mu \mathrm{M})$ and then dropped at higher doses whereas CSC enrichment following regorafenib remained elevated at higher doses. We then tested a benign leiomyoma (Figure 4D) to ascertain whether some of these effects could be attributed to the ex vivo digestion process. We observed no significant change in cell viability or the ALDH ${ }^{\text {bright }}$ population following sorafenib exposure.

Despite the variability between patient samples, we concluded from these data that sorafenib was directly cytotoxic to human primary sarcomas ex vivo with a corresponding increase in ALDH ${ }^{\text {bright }}$ cells, and our ex vivo results with pazopanib and regorafenib correlated with our results in vitro.

\section{Preoperative sorafenib enriches for CSCs in clinical sarcoma specimens}

We then analyzed ALDH1 staining by IHC from archived specimens of STS patients. We created a TMA using replicate cores of tumor tissue obtained from STS patients previously treated with neoadjuvant sorafenib and conformal RT on a Phase I clinical trial for patients with locally advanced disease amenable to treatment with curative intent (Clinical Trial Information: NCT\#00805727/ UCDCC\#216) [24]. Patients underwent a core biopsy to establish the diagnosis of STS (pre-treatment) followed by 5-6 weeks of preoperative treatment with sorafenib at one of two doses (200 mg bid and 200/400 daily) with concurrent RT. Surgical resection was performed 4-6 weeks following completion of neoadjuvant therapy.

Using matched patient tissue before and after sorafenib therapy, we observed increases in the ALDH1 score among all patients (Figure 5A). Moreover, the mean ALDH1 score increased significantly from $31 \pm 14$ pretreatment to $101 \pm 18$ post-treatment $(\mathrm{P}=0.003)$. We then evaluated ALDH1 staining intensity in a control cohort of STS patients who declined participation or were ineligible for NCT\#00805727/UCDCC\#216. These patients underwent diagnostic biopsy followed by definitive surgical resection without preoperative therapy. As shown in Figure 5C, using matched tissue from these patients, we observed no difference in the mean ALDH1 score from tumor tissue obtained at biopsy versus tissue obtained at surgical resection (biopsy mean ALDH1 score $46 \pm 34$ vs. resection mean score $44 \pm 27, \mathrm{P}=0.86$ ).

We then examined paired samples of tissue from a patient with metastatic STS who was treated with pazopanib and underwent surgical resection before and after treatment (Figure 5E). There was no significant difference in the percentage of ALDH ${ }^{\text {bright }}$ cells present in the specimen after pazopanib treatment, providing additional evidence from STS patients that sorafenib enriches for ALDH ${ }^{\text {bright }}$ sarcoma CSCs while pazopanib does not.

\section{Discussion}

Accumulating evidence suggests that CSCs exist as a sub-population of quiescent cells within the dominant tumor bulk of heterogeneous tumor cells $[1,12]$. These typically dormant cells are considered resistant to standard anti-cancer therapies such as chemotherapy and RT, and they appear capable of self-renewal and differentiation $[5,19,32,33]$, suggesting that CSCs are responsible for tumor repopulation after bulk tumor has been destroyed [3].

Numerous studies have focused on characterizing the behavior and phenotype of CSCs. Much attention has been devoted to demonstrating that the expression of cell surface markers, such as CD24, CD44, and CD133, and the activity of the intracellular enzyme ALDH consistently predict the CSC phenotype. In addition, the presence of CSCs, in general, and ALDH expression, in particular, has been shown to predict worse prognosis in numerous human cancers, such as breast, prostate, and kidney $[13,14,17]$. Despite this attention to the significance of CSCs, relatively few studies have examined the differences in anti-proliferative versus anti-angiogenic 


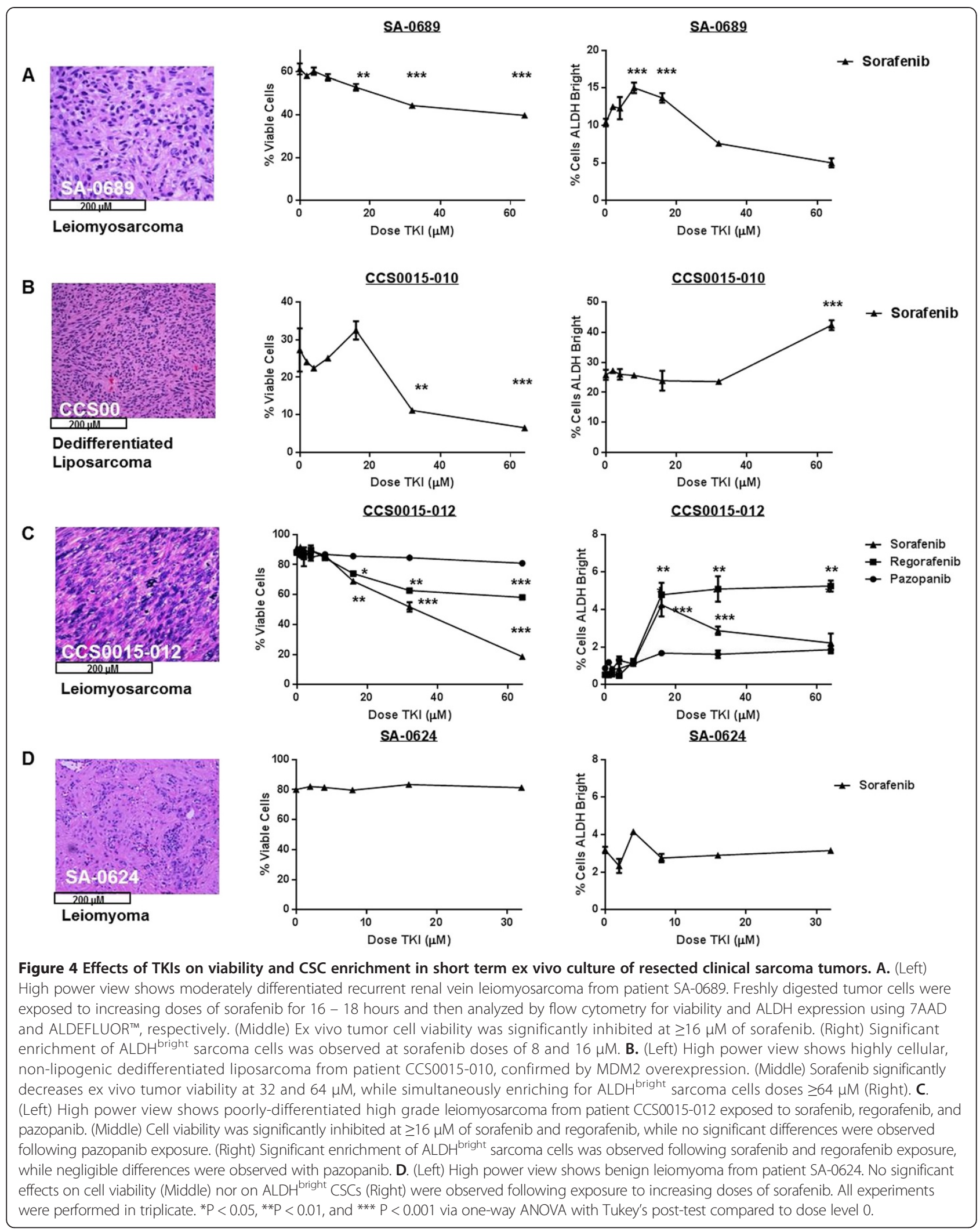




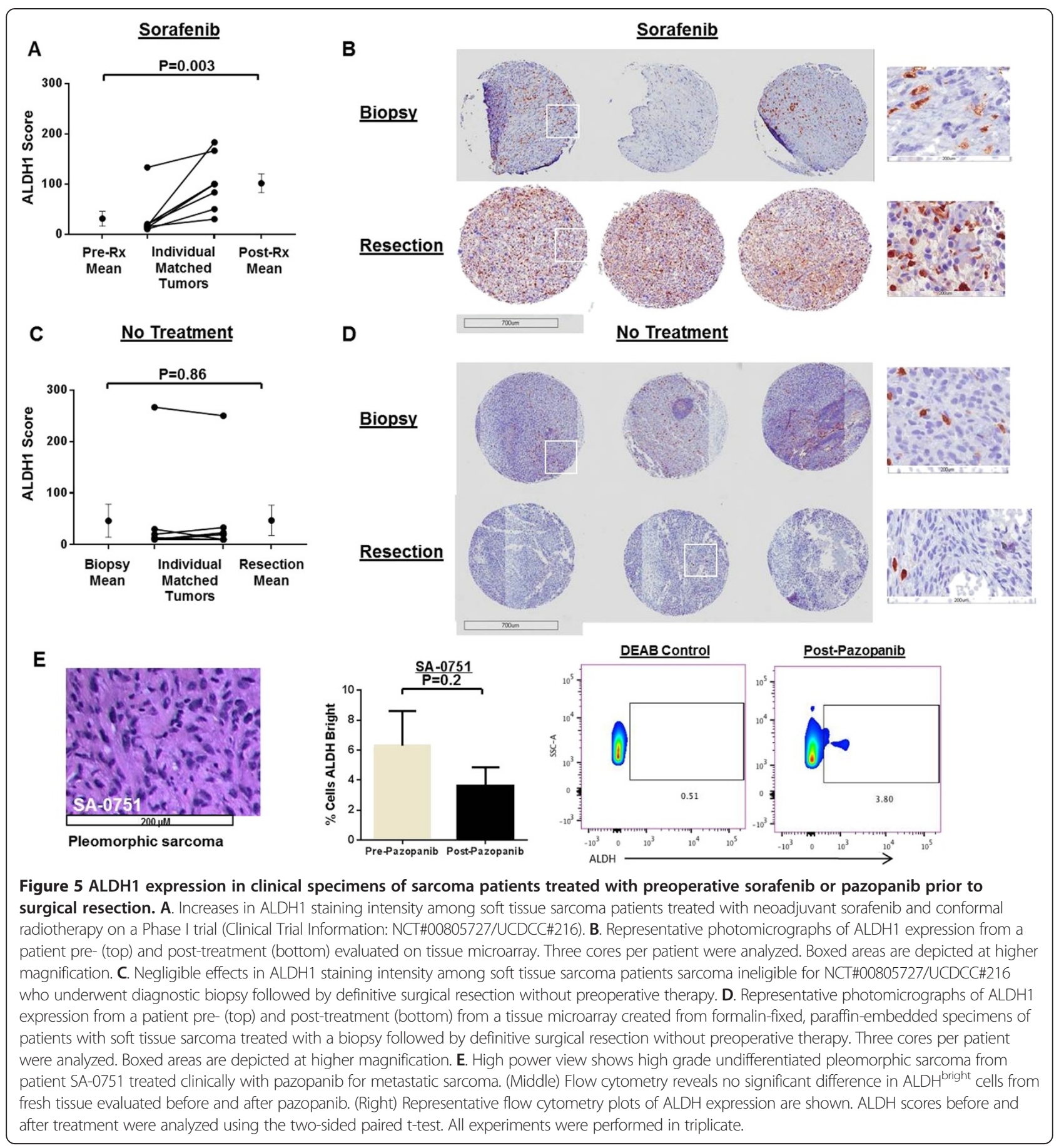

therapy on the evolution of CSC subpopulations over time in cell culture, xenograft models, or clinical specimens, particularly for STS.

In this study, we demonstrate that sorafenib and regorafenib, but not pazopanib, exert significant antiproliferative effects while simultaneously enriching for CSCs in multiple models of STS, including primary sarcoma cells freshly derived from surgical specimens. In addition, we observe enrichment of ALDH1-stained cells in matched tumor-specimens obtained before and after neoadjuvant therapy with sorafenib and RT, whereas there was no evidence of CSC enrichment following clinical treatment with pazopanib. Although CSCs are widely believed to be resistant to conventional cytotoxic therapies, such as chemotherapy and RT, there are relatively few studies which demonstrate similar effects with anti- 
proliferative TKIs, such as sorafenib. There are also limited data evaluating the differences on CSC enrichment between various TKIs.

Our study reinforces the concept that anti-proliferative therapies enrich for the CSC population in solid malignancies and that anti-proliferative TKIs may exert distinct anti-tumor strategies than anti-angiogenic ones. A major strength of our study is the substantial amount of data obtained from STS patients, including fresh STS specimens procured at the time of surgical resection as well as retrospectively from archived tumor specimens. These data emphasize the translational relevance of our work which suggests that CSC enrichment following TKI therapy with sorafenib may be a mechanism of tumor resistance. Consequently, we hypothesize that sustained and durable anti-sarcoma therapies will require concomitant targeting of CSCs.

These data also reinforce the broader concept that standard anti-proliferative therapies, including TKIs, target the proliferating non-CSCs while sparing, or possibly even promoting, the repopulation of CSCs. Our data also support the hypothesis that CSCs are a mechanism of resistance to standard anti-proliferative therapies since elimination of non-CSCs parallels the enrichment of CSCs.

Although we demonstrate a consistent pattern for the effects on sorafenib (distinct from pazopanib) on STS in diverse pre-clinical and human models, it is important to acknowledge several limitations of our study. Although the majority of STS subtypes share a common mesenchymal origin, STS are a heterogenous group of malignancies, and there is clearly a variation in ALDH expression from subtype to subtype as well as depending on the cell culture conditions. Despite this variability in ALDH expression, we focused on ALDH activity as a CSC marker since we could validate the phenotype of ALDH ${ }^{\text {bright }}$ CSCs. In contrast, similar to Chen et al., we observed that CD133 and CD44 did not reliably validate the CSC phenotype [34]. However, the variability of marker expression among CSCs depending on culture conditions as well as tumor histology does imply that we may have to adapt the techniques necessary to identify and target sarcoma CSCs by subtype and reinforces the concept of some critics that ALDH and other cell surface molecules only correlate with the CSC phenotype rather than causally mediate it $[12,35]$.

In addition, the majority of our pre-clinical data was obtained from a Ewing's sarcoma cell line (A673). This STS subtype is known to share many phenotypic properties with neuro-ectodermal cells [36]. Consequently, it is possible that our results with this cell line are biased by the overlap of A673 cells with neural progenitor tissue, which are known to harbor pluripotent stem cells [37]. Finally, our data from archived STS specimens treated on a neoadjuvant clinical protocol including sorafenib is confounded by the addition of RT to the treatment regimen. Although there is significant enrichment after sorafenib/RT compared to no treatment, it is conceivable that some, or the majority, of these effects is secondary to RT or the combination of sorafenib and RT, rather than sorafenib alone.

\section{Conclusion}

In summary, we demonstrate that in diverse sarcoma models, including extensive clinical sarcoma specimens, sorafenib exerts significant anti-proliferative effects while simultaneously enriching for CSCs, and pazopanib does not. These data indicate that TKIs have differential effects on CSC populations depending on their mechanism of action. Taken together, our results suggest that CSC enrichment following anti-proliferative TKI therapy is an apparent mechanism of tumor resistance. Therefore, sustained anti-sarcoma therapies may require concomitant targeting of CSCs.

\section{Additional files}

Additional file 1: Representative Flow Cytometry Plots of ALDH
Expression A. SW982 cells in vitro are shown. (Left)
Diethylaminobenzaldehyde (DEAB), a specific inhibitor of ALDH, is used
to control for background fluorescence. (Middle) Vehicle control. (Right)
Sorafenib 16 uM. B. A673 in vivo tumors harvested on treatment day 7
are shown. (Left) DEAB background fluorescence. (Middle) Placebo-treated
controls. (Right) Sorafenib 75 mg/kg.
Additional file 2: Figure S1. Validation of ALDH as a CSC marker in
A673 sarcoma cells. A. A673 cells were sorted by flow cytometry into
ALDH ${ }^{\text {bright }}$ and ALDH ${ }^{\text {dim }}$ populations. $2 \times 10^{5}$ purified cells were implanted
subcutaneously into contralateral flanks of NSG mice (N $=4$ ) and allowed to
grow. ALDH ${ }^{\text {bright }}$ cells established tumors faster and were more rapidly fatal.
*P $<0.05$. B. Representative photograph showing difference in tumor
formation between ALDH ${ }^{\text {bright }}$ and ALDH ${ }^{\text {dim }}$ A673 sarcoma cells sorted by
flow cytometry and implanted subcutaneously in NSG mice.
C. Representative T1- and T2-weighted MRI images demonstrating
difference in tumor formation between ALDH ${ }^{\text {bright }}$ and ALDH ${ }^{\text {dim }}$ A673
sarcoma cells sorted by flow cytometry and implanted subcutaneously
in NSG mice. D. Expression of CSC cell surface markers and ALDH in
representative STS cell lines.

\section{Abbreviations}

CSCs: Cancer stem cells; STS: Soft tissue sarcoma; ALDH: Aldehyde dehydrogenase; TMA: Tissue microarray; RT: Radiotherapy; TKIs: Tyrosine kinase inhibitors; i.p.: Intraperitoneal; DEAB: Diethylaminobenzaldehyde; FACS: Fluorescence-activated cell sorting; H\&E: Hematoxylin and eosin.

\section{Competing interests}

The authors declare that they have no conflicts of interest.

\section{Authors' contributions}

RJC, EA, SM, RCS, and JT performed in vitro experiments. RJC, EA, SM, SG, and JT performed in vivo experiments. RJC, EA, SM, and SG performed ex vivo analysis of human primary sarcomas. MC and DB evaluated histopathology and immunohistochemical staining. CSLi participated in the design of the study and assisted with the statistical analysis. RJC, EA, TJS, AMM, and WJM conceived of the study, participated in its design and coordination, and helped to draft the manuscript. All authors read and approved the final manuscript. 


\section{Acknowledgements}

This work was supported by funding from the National Institutes of Health (UC Davis Paul Calabresi K12 Career Development Award NIH 1K12CA138464-01A2, RJC), the National Center for Advancing Translational Sciences (\#UL1 TR000002, CSL), the Sarcoma Foundation of America (RJC), and the University of California Coordinating Committee for Cancer Control (RUC). We also thank Dr. Regina Gandour-Edwards, Irmgard Feldman, and Ramona Clarke from the Biorepository Core Facility at the University of California Davis Comprehensive Cancer Center, which also receives funding from the National Cancer Institute, for support with the acquisition and evaluation of human specimens.

This project has also been funded in part by the National Cancer Institute, National Institutes of Health, under contract HHSN26120080001E (TJS). The content of this publication does not necessarily reflect the views or policies of the Department of Health and Human Services, nor does the mention of trade names, commercial products, or organizations imply endorsement by the U.S. Government. This Research was also supported in part by the Intramural Research Program of the $\mathrm{NIH}$, National Cancer Institute, Center for Cancer Research.

\section{Author details}

'Department of Surgery, Division of Surgical Oncology, University of California Davis Medical Center, 4501 X Street, Sacramento, CA 95817, USA.

${ }^{2}$ Laboratory of Cancer Immunology, Department of Dermatology, University of California Davis Medical Center, Sacramento, CA 95817, USA. ${ }^{3}$ Department of Pathology and Laboratory Medicine, University of California Davis Medical Center, Sacramento, CA 95817, USA. ${ }^{4}$ Division of Biostatistics, Department of Public Health Sciences, University of California Davis, Sacramento, CA 95817, USA. ${ }^{5}$ Cancer and Inflammation Program, Leidos Biomedical Research, Inc, Frederick National Laboratory, Frederick, Maryland 21702, USA. ${ }^{6}$ Department of Radiation Oncology, University of California Davis Medical Center, Sacramento, CA 95817, USA. ${ }^{7}$ Department of Dermatology, University of California Davis Medical Center, Sacramento, CA 95817, USA.

Received: 17 July 2014 Accepted: 2 October 2014

Published: 10 October 2014

\section{References}

1. Visvader JE, Lindeman GJ: Cancer stem cells: current status and evolving complexities. Cell Stem Cell 2012, 10(6):717-728.

2. Ishizawa K, Rasheed ZA, Karisch R, Wang Q, Kowalski J, Susky E, Pereira K, Karamboulas C, Moghal N, Rajeshkumar NV, Hidalgo M, Tsao M, Ailles L, Waddell TK, Maitra A, Neel BG, Matsui W: Tumor-initiating cells are rare in many human tumors. Cell Stem Cell 2010, 7(3):279-282.

3. Chen J, Li Y, Yu TS, McKay RM, Burns DK, Kernie SG, Parada LF: A restricted cell population propagates glioblastoma growth after chemotherapy. Nature 2012, 488(7412):522-526.

4. Jiang X, Gwye Y, Russell D, Cao C, Douglas D, Hung L, Kovar H, Triche TJ, Lawlor ER: CD133 expression in chemo-resistant Ewing sarcoma cells. BMC Cancer 2010, 10:116.

5. Li X, Lewis MT, Huang J, Gutierrez C, Osborne CK, Wu MF, Hilsenbeck SG, Pavlick A, Zhang X, Chamness GC, Wong H, Rosen J, Chang JC: Intrinsic resistance of tumorigenic breast cancer cells to chemotherapy. J Nat Cancer Inst 2008, 100(9):672-679.

6. Charafe-Jauffret E, Ginestier C, Bertucci F, Cabaud O, Wicinski J, Finetti P, Josselin E, Adelaide J, Nguyen TT, Monville F, Jacquemier J, Thomassin-Piana J, Pinna G, Jalaguier A, Lambaudie E, Houvenaeghel G, Xerri L, Harel-Bellan A, Chaffanet M, Viens P, Birnbaum D: ALDH1-positive cancer stem cells predict engraftment of primary breast tumors and are governed by a common stem cell program. Cancer Res 2013, 73(24):7290-7300.

7. van den Hoogen C, van der Horst G, Cheung H, Buijs JT, Lippitt JM, Guzman-Ramirez N, Hamdy FC, Eaton CL, Thalmann GN, Cecchini MG, Pelger RC, van der Pluijm G: High aldehyde dehydrogenase activity identifies tumor-initiating and metastasis-initiating cells in human prostate cancer. Cancer Res 2010, 70(12):5163-5173.

8. Wang L, Park P, Zhang H, La Marca F, Lin CY: Prospective identification of tumorigenic osteosarcoma cancer stem cells in OS99-1 cells based on high aldehyde dehydrogenase activity. Int J Cancer 2011, 128(2):294-303.

9. Schepers AG, Snippert HJ, Stange DE, van den Born M, van Es JH, van de Wetering $\mathrm{M}$, Clevers $\mathrm{H}$ : Lineage tracing reveals Lgr5+ stem cell activity in mouse intestinal adenomas. Science 2012, 337(6095):730-735.
10. Driessens $G$, Beck B, Caauwe A, Simons BD, Blanpain C: Defining the mode of tumour growth by clonal analysis. Nature 2012, 488(7412):527-530.

11. Dela Cruz FS: Cancer stem cells in pediatric sarcomas. Front Oncol 2013, 3:168.

12. Valent $\mathrm{P}$, Bonnet $\mathrm{D}$, De Maria R, Lapidot $\mathrm{T}$, Copland M, Melo JV, Chomienne C, Ishikawa F, Schuringa JJ, Stassi G, Huntly B, Herrmann H, Soulier J, Roesch A, Schuurhuis GJ, Wöhrer S, Arock M, Zuber J, Cerny-Reiterer S, Johnsen HE, Andreeff $M$, Eaves $C$ : Cancer stem cell definitions and terminology: the devil is in the details. Nat Rev Cancer 2012, 12(11):767-775.

13. Charafe-Jauffret E, Ginestier C, lovino F, Tarpin C, Diebel M, Esterni B, Houvenaeghel G, Extra JM, Bertucci F, Jacquemier J, Xerri L, Dontu G, Stassi G, Xiao Y, Barsky SH, Birnbaum D, Viens P, Wicha MS: Aldehyde dehydrogenase 1-positive cancer stem cells mediate metastasis and poor clinical outcome in inflammatory breast cancer. Clin Cancer Res 2010, 16(1):45-55.

14. Deng S, Yang X, Lassus H, Liang S, Kaur S, Ye Q, Li C, Wang LP, Roby KF, Orsulic S, Connolly DC, Zhang Y, Montone K, Bützow R, Coukos G, Zhang L: Distinct expression levels and patterns of stem cell marker, aldehyde dehydrogenase isoform 1 (ALDH1), in human epithelial cancers. PLoS One 2010, 5(4):e10277.

15. Ginestier $C$, Hur MH, Charafe-Jauffret $E$, Monville F, Dutcher J, Brown M, Jacquemier J, Viens P, Kleer CG, Liu S, Schott A, Hayes D, Birnbaum D, Wicha MS, Dontu G: ALDH1 is a marker of normal and malignant human mammary stem cells and a predictor of poor clinical outcome. Cell Stem Cell 2007, 1(5):555-567.

16. Kitamura H, Torigoe T, Hirohashi Y, Asanuma H, Inoue R, Nishida S, Tanaka T, Fukuta F, Masumori N, Sato N, Tsukamoto T: Prognostic impact of the expression of ALDH1 and SOX2 in urothelial cancer of the upper urinary tract. Mod Pathol 2013, 26(1):117-124.

17. Le Magnen C, Bubendorf L, Rentsch CA, Mengus C, Gsponer J, Zellweger T, Rieken M, Thalmann GN, Cecchini MG, Germann M, Bachmann A, Wyler S, Heberer M, Spagnoli GC: Characterization and clinical relevance of ALDHbright populations in prostate cancer. Clin Cancer Res 2013, 19(19):5361-5371.

18. Li T, Su Y, Mei Y, Leng Q, Leng B, Liu Z, Stass SA, Jiang F: ALDH1A1 is a marker for malignant prostate stem cells and predictor of prostate cancer patients' outcome. Lab Invest 2010, 90(2):234-244.

19. Awad O, Yustein JT, Shah P, Gul N, Katuri V, O'Neill A, Kong Y, Brown ML, Toretsky JA, Loeb DM: High ALDH activity identifies chemotherapyresistant Ewing's sarcoma stem cells that retain sensitivity to EWS-FLI inhibition. PLoS One 2010, 5(11):e13943.

20. Wilhelm SM, Carter C, Tang L, Wilkie D, McNabola A, Rong H, Chen C, Zhang X, Vincent P, McHugh M, Cao Y, Shujath J, Gawlak S, Eveleigh D, Rowley B, Liu L, Adnane L, Lynch M, Auclair D, Taylor I, Gedrich R, Voznesensky A, Riedl B, Post LE, Bollag G, Trail PA: BAY 43-9006 exhibits broad spectrum oral antitumor activity and targets the RAF/MEK/ERK pathway and receptor tyrosine kinases involved in tumor progression and angiogenesis. Cancer Res 2004, 64(19):7099-7109.

21. Hasskarl J: Sorafenib: targeting multiple tyrosine kinases in cancer. Recent Results Cancer Res 2014, 201:145-164.

22. Maki RG, D'Adamo DR, Keohan ML, Saulle M, Schuetze SM, Undevia SD, Livingston MB, Cooney MM, Hensley ML, Mita MM, Takimoto CH, Kraft AS, Elias AD, Brockstein B, Blachère NE, Edgar MA, Schwartz LH, Qin LX, Antonescu CR, Schwartz GK: Phase II study of sorafenib in patients with metastatic or recurrent sarcomas. Clin Cancer Res 2009, 27(19):3133-3140.

23. von Mehren M, Rankin C, Goldblum JR, Demetri GD, Bramwell V, Ryan CW, Borden E: Phase 2 Southwest Oncology Group-directed intergroup trial (S0505) of sorafenib in advanced soft tissue sarcomas. Cancer 2012, 118(3):770-776.

24. Canter RJ, Borys D, Olusanya A, Li CS, Lee LY, Boutin RD, Christensen SD, Tamurian RM, Monjazeb AM: Phase I trial of Neoadjuvant conformal radiotherapy plus sorafenib for patients with locally advanced soft tissue sarcoma of the extremity. Ann Surg Oncol 2014, 21(5):1616-1623.

25. Hamed HA, Tavallai S, Grant S, Poklepovic A, Dent P: Sorafenib/Regorafenib and Lapatinib interact to kill CNS tumor cells. J Cell Physiol 2015, 230(1):131-139.

26. Ettrich TJ, Seufferlein T: Regorafenib. Recent Results Cancer Res 2014, 201:185-196.

27. Ranieri G, Mammi M, Donato Di Paola E, Russo E, Gallelli L, Citraro R, Gadaleta CD, Marech I, Ammendola M, De Sarro G: Pazopanib a tyrosine kinase inhibitor with strong anti-angiogenetic activity: a new treatment 
for metastatic soft tissue sarcoma. Crit Rev Oncol Hematol 2014, 89(2):322-329.

28. van der Graaf WT, Blay JY, Chawla SP, Kim DW, Bui-Nguyen B, Casali PG, Schoffski P, Aglietta M, Staddon AP, Beppu Y, Le Cesne A, Gelderblom H, Judson IR, Araki N, Ouali M, Marreaud S, Hodge R, Dewji MR, Coens C, Demetri GD, Fletcher CD, Dei Tos AP, Hohenberger P, EORTC Soft Tissue and Bone Sarcoma Group; PALETTE study group: Pazopanib for metastatic soft-tissue sarcoma (PALETTE): a randomised, double-blind, placebocontrolled phase 3 trial. Lancet 2012, 379(9829):1879-1886.

29. McCormack PL: Pazopanib: a review of its use in the management of advanced renal cell carcinoma. Drugs 2014, 74(10):1111-1125.

30. Guryanova OA, Wu Q, Cheng L, Lathia JD, Huang Z, Yang J, MacSwords J, Eyler CE, McLendon RE, Heddleston JM, Shou W, Hambardzumyan D, Lee J, Hjelmeland AB, Sloan AE, Bredel M, Stark GR, Rich JN, Bao S: Nonreceptor tyrosine kinase BMX maintains self-renewal and tumorigenic potential of glioblastoma stem cells by activating STAT3. Cancer Cell 2011, 19(4):498-511.

31. Plastaras JP, Kim SH, Liu YY, Dicker DT, Dorsey JF, McDonough J, Cerniglia G, Rajendran RR, Gupta A, Rustgi AK, Diehl JA, Smith CD, Flaherty KT, El-Deiry WS: Cell cycle dependent and schedule-dependent antitumor effects of sorafenib combined with radiation. Cancer Res 2007, 67(19):9443-9454.

32. Honoki K, Fujii H, Kubo A, Kido A, Mori T, Tanaka Y, Tsujiuchi T: Possible involvement of stem-like populations with elevated ALDH1 in sarcomas for chemotherapeutic drug resistance. Oncol Rep 2010, 24(2):501-505.

33. Tanei T, Morimoto K, Shimazu K, Kim SJ, Tanji Y, Taguchi T, Tamaki Y, Noguchi S: Association of breast cancer stem cells identified by aldehyde dehydrogenase 1 expression with resistance to sequential Paclitaxel and epirubicin-based chemotherapy for breast cancers. Clin Cancer Res 2009, 15(12):4234-4241.

34. Chen J, Guo T, Zhang L, Qin LX, Singer S, Maki RG, Taguchi T, Dematteo R, Besmer P, Antonescu CR: CD133 and CD44 are universally overexpressed in GIST and do not represent cancer stem cell markers. Genes Chromosomes Cancer 2012, 51(2):186-195.

35. Trucco M, Loeb D: Sarcoma stem cells: do we know what we are looking for? Sarcoma 2012, 2012:291705.

36. Lipinski M, Braham K, Philip I, Wiels J, Philip T, Goridis C, Lenoir GM, Tursz T: Neuroectoderm-associated antigens on Ewing's sarcoma cell lines. Cancer Res 1987, 47(1):183-187.

37. Moody SA, Klein SL, Karpinski BA, Maynard TM, Lamantia AS: On becoming neural: what the embryo can tell us about differentiating neural stem cells. Am J Stem Cells 2013, 2(2):74-94.

doi:10.1186/1471-2407-14-756

Cite this article as: Canter et al:: Anti-proliferative but not anti-angiogenic tyrosine kinase inhibitors enrich for cancer stem cells in soft tissue sarcoma. BMC Cancer 2014 14:756.

\section{Submit your next manuscript to BioMed Central and take full advantage of:}

- Convenient online submission

- Thorough peer review

- No space constraints or color figure charges

- Immediate publication on acceptance

- Inclusion in PubMed, CAS, Scopus and Google Scholar

- Research which is freely available for redistribution 